be done, will not the conjecture amount almost to certainty, that the iliac was punctured, and not ruptured, in this exceedingly mysterious, complicated, and mistaken case?

Portsea, August, 1848.

\section{TREATMENT OF MEDICAL PRACTITIONERS UNDER THE POOR.LAW.}

To the Editor of THE LANCET.

Sir,-I have sent you a copy of the correspondence with the poor-law board, connected with one of the subjects mentioned in Lord Ashley's resolutions, and shall feel much obliged by its insertion in THE LANCET.

Hurstperpoint, July 26,1848 .

$$
\text { I am, Sir, your obedient servant, }
$$
H. Martrn Holman, M.D.

\section{To the Poor-law Board, Somerset House.}

Gentuemen,-During last month I was called in consultation with one of the medical officers of the Cuckfield Union. The case was that of a woman who had been in labour fortyeight hours, and whose case both of us agreed required instrumental assistance. After failing to deliver her with the forceps, we delivered her by performing the operation of craniotomy. Now I am desirous of knowing whether the board of guardians would be justified in paying me a fee for my attendance, in addition to the fee of two pounds which the medical officer whose case it was will be entitled to under the medical order, and which will be more than earned by the after attendance. I was offered half the fee, or the whole of it, by the medical officer; but of course I could not think of receiving anything from him, as he had lost much more time over the case than I did. I have not applied to the board of guardians for any remuneration, as I am desirous of knowing, before doing so, whether they would be authorized to allow me any.-I am, gentlemen, your obedient servant,

Hurstperpoint, July 11, 1848. H. Martin Holuan.

Poor-law Board, Somerset House, July 15,1848 .

Sir,-I am directed by the poor-law board to acknowledge the receipt of your letter of the 11 th inst., and to inform you, that if your assistance in the cass of midwifery therein referred to was asked for by the medical officer, and not by the guardians of the Cuclifield Union, this board fear that the guardians have no legal power to pay you any fee for the services which you appear to have so readily rendered in the case.-I am, Sir, your obedient servant,

To H. M. Holman, Esq., M.D.

Hurstperpoint, Sussex.

\section{Ebrinaton, Sec.}

Hurstperpoint, July 26,1848 .

Gentlemen,--In reply to your letter of the 15 th July, 1848 , I beg to state, that when I was called in consultation in the midwifery case alluded to, it would have been inpossible to have been sent for by the direction of the board of guardians, as their day of meeting would not take place until some days after the case happened; and had the assistance been deferred until then, the woman would most probably have been dead, as in such a case the assistance required must be prompt and efficient; and I believe that in a case like the one alluded to there are very few medical men who would like to act solely on their own judgment. I was induced to make an application to the poor-law board for their sanction of a fee being paid, from what had fallen from Mr.Buller, in the debate on Lord Ashley's resolutions, in which he stated he would sanction the payment of a fee to the consultant, in a case where so serious an operation as craniotomy was obliged to be performed. It now only remains for me to give as much publicity as I can to my correspondence with the poor-law board, as a caution to medical men not to act as consultants in such cases, unless specially directed by boards of guardians, unless they do not mind performing so unpleasant and serious an operation with out any hope of remuneration.

I am, gentlemen, your obedient servant

To the Poor-law Board.

H. Martla Holman, M.D.

\section{THE UPTON-ON-SEVERN UNION.}

To the Editor of THE LANCET.

Copy of a Letter to the Chairman of the Board of Guardians of the Upton-on-Severn Union.

SrR,-At the present juncture it may not be inopportune to lay before you, very respectfully, an enclosed statistical table of the amount of duty which a medical officer has to perform, and the very extensive supplies which he must necessarily furnish. I hesitate not to say, from some practical experience in the matter, (if seeing with my own eyes, and furnishing aid with my own hands, can be called experience, ) that medical relief, instead of being administered in a liberal and just spirit by so-called guardians of the poor, is borne almost exclusively by the medical officer. $\mathrm{He}$ it is who has to endure the heat and burden of the day, and the chilly fogs of night, - he it is who can never call half an hour strictly his own,-he it is who, when he retires to rest at night, must place his candle and match-box ready, in order to obey any hasty summons. The very expectation of being roused often destroys the disposition for sleep.

I positively declare that I should be ashamed of the stamp of manhood I bear, if I were to insist on the lowest menial in existence performing the duty which I myself have to undergo for the wretched pay which is ignorantly meted out. I repeat, I should be thoroughly ashamed of my inhumanity: and I cannot but admire that unanimous display of spirit which, rather than permit your medical officers to submit to this grinding degradation, has nobly prompted them to throw up their several appointments. For the honour of the profession, and for the attainment of an ordinary degree of justice, $X$ trust no medical man will be found so inconsiderate-nay, suicidal-as to offer his services in opposition to so just a movement.

Boards of guardians cannot be expected to know anything of medical relief, or they would take a very different view of this important subject. They grind down the salary of the medical officer in a most unjust way, and when, at last, that functionary is so galled as to be compelled to seek redress, boards of guardians only subject him to contrimely, and, in some cases, to gross insolence.

These remarks may not be very palatable; but, Sir, they come from one who can sympathize most keenly with his brother medical officers, wherever situate, - and from one, too, who will never cease, so long as life is granted, to advocate justice--open-handed, liberal justice-to the hard-worked, but ill-remunerated, medical attendant on the poor.-I have the honour to be, Sir, your very obedient, humble servant, Halifax, August, 1848. Frederick Smith Garlick.

To the Editor of ThE LaNoET.

SrR,-Deep are my feelings of indignation, contempt, and disgust, for those members of our profession who have applied to be elected to the Upton-upon-Severn Union. Perhaps Messrs. Braddon and White will, through the medium of your journal, forward, for the information of the public, the Christian and surnames of all the candidates, that they may be published in capital letters, in an early number of THE LANCET, and so be held up to the scorn of all honourable surgeons.

Further than this: I belong to a numerous and influential medical society, and I shall take an early opportunity of proposing a resolution that the names be registered in the archives of our society, and that, should any one of them, by any chance, at a future period, propose to join such society, his name be as a matter of course blackballed. Let the same plan be adopted throughout the length and breadth of the land, as a very slight and inadequate means of giving expression to a just indignation. True it is that laws were never made for men of honour: the necessity for my plan ought not to exist; its adoption is humiliating in the extreme; it is a confession of our rottenness, disunion, and want of gentlemanly feeling. But we must look to the necessity alone, not to the disgrace that such necessity should exist.

Aug. 7th, 1848 I am, Sir, your obedient servant, AN OLD ADMIRER.

\section{THANKS OF DR. BERNCASTLE TO HIS PROFES-} SIONAL BRETHREN.

To the Editor of THE LANCET.

SIR,-Allow me, through the medium of your pages, to return my most heartfelt thanks to the medicaloprofession for the very liberal and unanimous support I have received from its members throughout the kingdom, in the late Croydon inquest. To your able advocacy of my cause, conjointly with the other members of the medical press, I am mainly indebted for my entire justification before the public, and triumph over the unfounded and unjust attack of the coroner, jury, and board of guardians upon my character.

The untiring and generous exertions of Mr. Steel, of Lewisham, in behalf of one of his injured medical brethren, will for ever endear his name to the profession, and it will be 